\title{
Congenital Rhabdomyosarcoma: a different clinical presentation in two cases
}

\author{
Ida Russo ${ }^{1^{*}}$ (D), Virginia Di Paolo', Carmelo Gurnari', Angela Mastronuzzi ${ }^{1}$, Francesca Del Bufalo', \\ Pier Luigi Di Paolo², Angela Di Giannatale ${ }^{1}$, Renata Boldrini ${ }^{3}$ and Giuseppe Maria Milano ${ }^{1}$
}

\begin{abstract}
Background: Rhabdomyosarcoma (RMS), one of the most common soft tissue sarcomas of childhood, is very rare in the neonatal period (0.4-2\% of cases). In order to gain a deeper understanding of this disease at such age, patient and tumor features, as well as treatment modality and outcome need to be reported.

Case presentation: We describe two cases with congenital RMS treated at Bambino Gesù Children's Hospital between 2000 and 2016. They represent only 2.24\% of all RMS patients diagnosed during that period in our Institution; this data is in agreement with the incidence reported in the literature. They reflect the two different clinical forms in which the disease may manifest itself. One patient, with the alveolar subtype (positive for specific PAX3-FOXO1 fusion transcript) and disseminated disease, had a fatal outcome with central nervous system (CNS) progression despite conventional and high dose chemotherapy. The other child, with the localized embryonal subtype, was treated successfully with conservative surgery and conventional chemotherapy, including prolonged maintenance therapy. He is disease free at 7 years of follow-up.

Conclusions: RMS can also be diagnosed during the neonatal period. Given the young age, disease management is often challenging, and especially for the alveolar subtype, the outcome is dismal despite intensified multimodality therapy. In fact, it characteristically manifests with multiple subcutaneous nodules and progression most commonly occurs in the CNS (Rodriguez-Galindo et al., Cancer 92(6):1613-20, 2001). In this context, CNS prophylaxis could play a role in preventing leptomeningeal dissemination, and molecular studies can allow a deeper tumor characterization, treatment stratification and identification of new potential therapeutic targets.
\end{abstract}

Keywords: Rhabdomyosarcoma, Newborn, Rare disease

\section{Background}

Rhabdomyosarcoma (RMS) is one of the most common soft tissue sarcomas of childhood. In $5-10 \%$ of cases, it is diagnosed in children aged less than one year old, and may be congential in $0.4-2 \%$ [1-3]. Various reports indicate that, when the diagnosis occurs in the neonatal period, the prognosis is worse than in older children [2-7]. We retrospectively reviewed the medical records of 89 children affected by RMS treated between 2000 and 2016 at our Department and, among these, we found two congenital cases. We report the clinical, radiological and histological characteristics of these patients, as well as

\footnotetext{
* Correspondence: ida.russo@opbg.net

'Department of Pediatric Hematology/Oncology, Bambino Gesù Children's

Hospital, IRCCS, Piazza di Sant'Onofrio 4, 00165 Rome, Italy

Full list of author information is available at the end of the article
}

therapeutic approach and outcome, together with a literature review of congenital RMS.

\section{Case presentation \\ Case \#1}

A full term newborn girl presented with widespread multiple nodular cutaneous and subcutaneous lesions on the head, limbs and trunk. Her mother's pregnancy as well as family history were unremarkable. The color of the lesions ranged from bluish to purple, a characteristic of the so-called "blueberry muffin lesions". She had no dysmorphic features or congenital anomalies. Excisional biopsy of one skin lesion showed a small-round-cell tumor, with an alveolar pattern of growth consistent with alveolar RMS (ARMS). Array-CGH analysis of tumor cells detected the specific PAX3-FOXO1 fusion transcript. Computed tomography (CT) revealed

(c) The Author(s). 2018 Open Access This article is distributed under the terms of the Creative Commons Attribution 4.0 International License (http://creativecommons.org/licenses/by/4.0/), which permits unrestricted use, distribution, and reproduction in any medium, provided you give appropriate credit to the original author(s) and the source, provide a link to the Creative Commons license, and indicate if changes were made. The Creative Commons Public Domain Dedication waiver (http://creativecommons.org/publicdomain/zero/1.0/) applies to the data made available in this article, unless otherwise stated. 
multiple lesions in the liver, pancreas, lungs, thoracic and abdominal walls (Fig. 1). A magnetic resonance image of the brain and spine showed a left retro-orbital mass and a paravertebral lumbosacral lesion. Bonemarrow and bones were positive for disease localization. After disease staging no primary site could be detected and the tumor was regarded as multifocal. The child was classified as group IV according to the Intergroup Rhabdomyosarcoma Study Group (IRSG) classification, and as stage IV according to TNM pretreatment staging classification [8]. She started chemotherapy with vincristine, actinomycin-D and cyclophosphamide (age and weight adapted doses). She presented a mixed response after 4 courses: complete remission in bone-marrow, skin and subcutaneous nodules; partial response of visceral, retro-orbital and lumbosacral lesions; leptomeningeal and pericardial progression. Following a discussion with the family and their request for further treatment, the child underwent chemotherapy with ifosfamide, vincristine, actinomycin-D, doxorubicin and intrathecal liposomial cytarabine arabinoside. The patient achieved complete remission of leptomeningeal and pericardial disease after 4 courses. Subsequently, she received highdose consolidation therapy with busulfan and melphalan followed by autologous stem cell transplantation.
Unfortunately, after one month, she presented central nervous system (CNS) recurrence and died of disease progression at 9 months of age.

\section{Case \#2}

A 5-day-old boy presented an abdominal mass in the hypogastric region. His mother's full-term pregnancy was uncomplicated. Physical examination and routine neonatal laboratory values were normal. Ultrasound of the abdomen and pelvis showed a solid mass (greatest diameter was $>5 \mathrm{~cm}$ ) located between the posterior bladder wall and sacrum. No family history of cancer was reported. On the assumption that the lesion was of benign nature, the child underwent macroscopically complete surgical excision of the mass. Intraoperatively, the tumor was found to originate from the prostate gland. The pathological examination revealed an embryonal RMS (ERMS). Molecular studies regarding the tumour with real time polymerase chain reaction (RT-PCR) did not reveal any PAX3-FOXO1 and PAX7-FOXO1 fusion transcripts. The child was classified as group II according to the IRSG classification and stage III according to the TNM pretreatment staging classification [8]. According to the European ongoing protocol (NCT\#00339118) for older children, he started

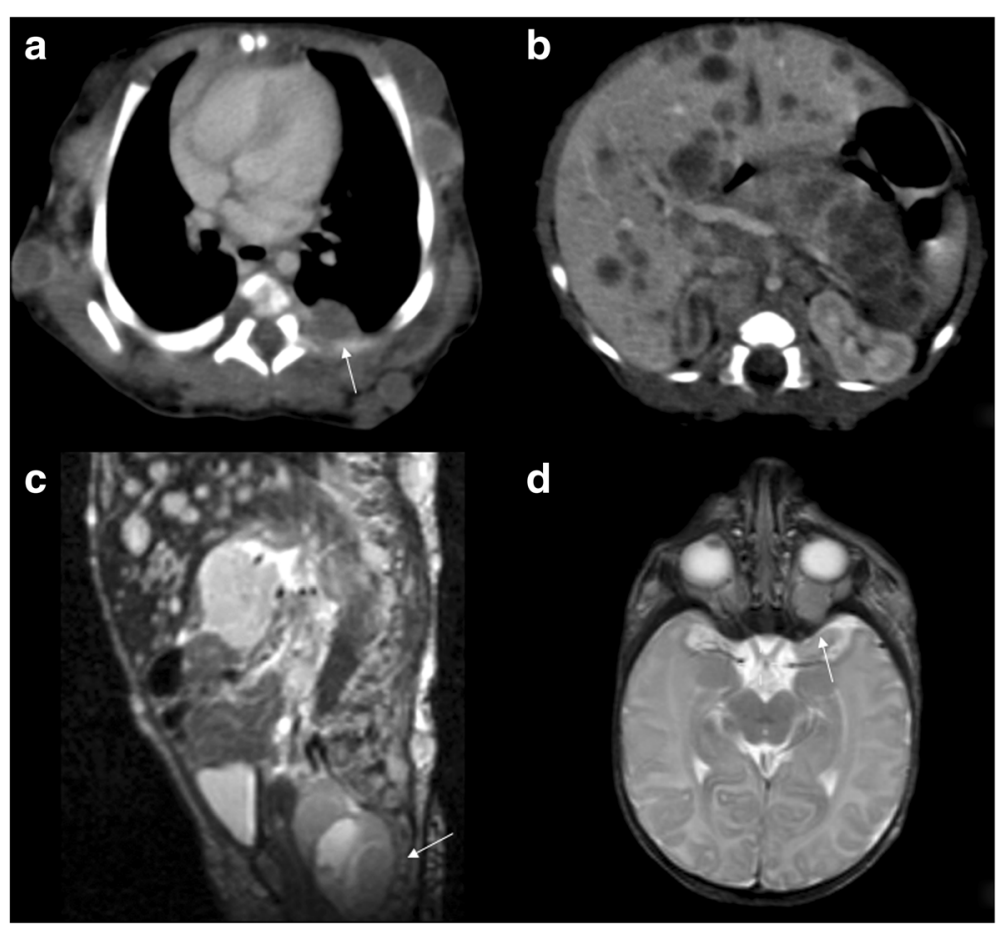

Fig. 1 a Axial contrast-enhanced CT image shows a multiple soft tissue masses in the subcutaneous fat with peripheral enhancement; some of these masses expand in the muscles. In the left posterior part of the chest the mass can be seen to lie slightly lateral to the paravertebral region (white arrow). b Axial, contrast-enhanced CT shows multiple low-density masses in the right and left lobes of the liver and in the pancreas. c Sagittal T2-weighted MR imaging shows a lobulated, hyperintense presacral mass (white arrow). d Axial T2-weighted MR imaging shows heterogeneous hyperintense intraorbital mass (white arrow) 
chemotherapy with 9 courses of vincristine, actinomycin$\mathrm{D}$ and ifosfamide (age and weight adapted doses). Due to paralytic ileus, vincristine was reduced by $50 \%$ from the third course onwards. Considering the young age, radiotherapy was not delivered. Thus, it was decided to use a prolonged maintenance therapy with 6 cycles of cyclophosphamide and vinorelbine. He is disease free at 7 years of follow-up and is doing well except for mild neurogenic bladder dysfunction.

\section{Discussion and conclusion}

Congenital RMS is a very rare neoplasia, as confirmed by data collected in our Institution over a 16-year period: only $2.24 \%$ of all RMS patients were diagnosed with the congenital form. We also performed a comprehensive PubMed search and 33 reports of congenital RMS (16 ERMS and 17 ARMS) published in the last 30 years were found and reviewed (Table 1). ERMS [9-22] ARMS [23-32]

The most frequent primary site for ARMS was the extremities, whereas for ERMS it was non-parameningeal head and neck. The two cases we reported represent the two different clinical forms in which the disease may manifest itself. While congenital ERMS is often localized and has the same behavior as that observed in older children, congenital ARMS is a highly malignant tumor, often occurring as a disseminated disease (see Case \#1). Moreover, ARMS often evolves with the development of brain metastases despite an initial good response to chemotherapy [23, 24]. For case \#1, in order to obtain CNS disease remission, we used intrathecal liposomial cytarabine arabinoside, and given the well-known dismal prognosis of the disease and the absence of other suitable alternatives, we decided to use consolidation highdose chemotherapy. However, the results with high-dose chemotherapy reported in previous published trials, did not show significant benefits in metastatic RMS [33, 34]. Currently, there are no specific guidelines regarding treatment for neonates and infants with sarcoma, with few exceptions, such as that of infantile fibrosarcoma [35]. Infants with RMS are usually treated according to the same protocols used for older children: mainly alkylating agents, vincristine, actinomycin-D, with or without anthracyclines. However, they require tailored treatments given the physiologic immaturity of various organs. Ragab et al. [2] reported an unacceptable toxicity compared with results in older children (5\% versus $1 \%$ of treatment-related deaths), when full chemotherapy doses were used in infants treated in the IRSG I and II trials. Chemotherapy dose reduction in infants resulted in less fatal toxicities without affecting the overall outcome $[1,3,4]$. Moreover, to avoid cardiac and renal damage, anthracyclines and ifosfamide are omitted in patients less than 3 and 1 months old respectively. With
Table 1 Congenital Rhabdomyosarcoma: review of the literature

\begin{tabular}{|c|c|c|}
\hline $\begin{array}{l}\text { Patient and disease } \\
\text { characteristics }\end{array}$ & $\begin{array}{l}\text { ERMS pts } \\
(n=16)\end{array}$ & $\begin{array}{l}\text { ARMS pts }^{\mathrm{e}} \\
(n=17)\end{array}$ \\
\hline $\begin{array}{l}\text { Gender: female/male } \\
\text { (sex ratio) }\end{array}$ & $5 / 11(0.45)$ & $10 / 7(1.4)$ \\
\hline \multicolumn{3}{|l|}{ Primary site } \\
\hline PM head \& neck & - & 1 \\
\hline Non PM head \& neck & 6 & 4 \\
\hline Orbit & - & - \\
\hline GU non bladder-prostate & 2 & - \\
\hline GU bladder-prostate & 2 & - \\
\hline Extremities & 1 & 7 \\
\hline Other site & $5^{\mathrm{a}}$ & $4^{b}$ \\
\hline NA & - & 1 \\
\hline \multicolumn{3}{|l|}{ IRSG } \\
\hline I & 1 & - \\
\hline$\|$ & 4 & 1 \\
\hline III & 11 & 3 \\
\hline IV & 1 & $13^{c}$ \\
\hline \multicolumn{3}{|l|}{ Molecular biology } \\
\hline Negative & 2 & 5 \\
\hline NA & 12 & 8 \\
\hline PAX3-FOXO1 positive & - & 3 \\
\hline PAX7-FOXO1 positive & - & - \\
\hline Others & $2[\mathrm{t}(2 ; 8)]$ & 1 [N-myc amplification] \\
\hline \multicolumn{3}{|l|}{ Therapy } \\
\hline NA & - & 1 \\
\hline Surgery only & 2 & - \\
\hline Chemotherapy only & 2 & 9 \\
\hline Chemotherapy + surgery & 9 & 4 \\
\hline $\begin{array}{l}\text { Chemotherapy + surgery + } \\
\text { radiotherapy }\end{array}$ & 3 & 2 \\
\hline $\begin{array}{l}\text { Chemotherapy + } \\
\text { radiotherapy }\end{array}$ & - & 1 \\
\hline \multicolumn{3}{|l|}{ Outcome } \\
\hline $\begin{array}{l}\text { Alive [median months } \\
\text { from dg (range)] }\end{array}$ & $8[31.5(6-240)]$ & $4[9(6-240)]$ \\
\hline Dead & 2 & $13^{d}$ \\
\hline NA & 6 & - \\
\hline
\end{tabular}

ERMS embryonal rhabdomyosarcoma, ARMS alveolar rhabdomyosarcoma, pts. patients, $P M$ parameningeal, $n$ number, GU genito-urinary, NA not available, IRSG Intergroup Rhabdomyosarcoma Study Group, $d g$ diagnosis

a 2-perineal, 2-chest wall, 1-trunk

b-trunk, 2-chest wall

'For all patients, cutaneous and subcutaneous tissue was a metastatic site

$\mathrm{d}^{\mathrm{d} / 13}$ patients had central nervous system disease progression

${ }^{\mathrm{e}}$ Data about family history of cancer were not available

regards to the management of congenital ARMS, we hypothesized that children affected by this disease, could benefit from early use of chemotherapeutic agents with good blood-brain barrier passage as well as early 
intrathecal chemotherapy, as one of the main causes of treatment failure is CNS progression. Local control, determined by extended surgery and radiotherapy, also poses special challenges in very young children due to possible sequelae. In the literature (Table 1), only 3 out of 16 patients with congenital ERMS received radiotherapy associated with conservative surgery (one of them was a female with a vaginal primary who underwent brachytherapy) [23]. Given the small number of patients and the lack of follow-up data in about one third of cases (6\16), no conclusion can be drawn concerning the outcome. The Italian Cooperative Group reported a higher local recurrence rate in infants with RMS who did not receive appropriate local treatment [1]. In our ERMS patient, since radiotherapy was not recommended, we decided to prolong treatment with maintenance chemotherapy. In this context, our decision was taken in order to consolidate disease remission. The potential role of maintenance therapy in this setting is intriguing but impossible to define given the anecdotal nature of our case. Few data are available regarding tumor biology and fusion status, being reported in only 13 out of 33 cases (Table 1). Gene profiling, currently mandatory in RMS, is even more important in congenital forms, which present a challenging disease. In fact, it could allow more accurate prognostic predictions, as well as detection of new molecular targets. In this regard, molecular prognostic factors have already been identified for a subgroup of congenital RMS, namely the spindle-cell type [36]; the tumors carrying NCOA2 gene rearrangements indeed showed a more favorable clinical course.

In conclusion, although rarely, RMS can also arise in the neonatal period. In these patients, it is often difficult to establish a balance between the necessity to cure and the risk of long-term effects. A large effort to elaborate guidelines/protocols is desirable to homogenize treatment for this rare tumor occurring within this age group. From experience gathered in the 2 reported cases, early CNS prophylaxis should be considered for the alveolar subtype and prolonged maintenance chemotherapy rather than radiotherapy might be envisaged for the localized embryonal type. Moreover, deeper molecular biology studies are crucial for tumor characterization, treatment stratification and for the discovery of new therapeutic targets.

\section{Abbreviations}

AIEOP: Italian Association of Pediatric Hematology/Oncology; ARMS: Alveolar Rhabdomyosarcoma; Array-CGH: Array - Comparative Genomic Hybridization; CT: Computed tomography; ERMS: Embryonal Rhabdomyosarcoma;

IRSG: Intergroup Rhabdomyosarcoma Study Group; RMS: Rhabdomyosarcoma

\section{Acknowledgments}

We thank Doctor Daniel Orbach for the critical reading of this paper and suggestions, the child's parents who gave informed consent for publication, "Il cuore grande di Flavio Onlus" for the research support, and Valentina Silenzi for editing.
Availability of data and materials

All data generated and analyzed during this study are included in this published article.

\section{Authors' contributions}

IR: collected the patient data, conducted the literature review, drafted the initial manuscript, and edited the manuscript according to feedback of the other authors. VDP: conducted the literature review, drafted the initial manuscript, and edited the manuscript according to feedback from the other authors. CG: reported clinical patient data, drafted the initial manuscript. AM and FBD: critically reviewed the manuscript. PLDP: performed the radiological image and legend, and critically reviewed the manuscript. ADG: collaborated with the design of the project, followed and supported indication for the manuscript realization, critically reviewed the manuscript. RB: performed histological diagnosis and critically reviewed the manuscript. GMM:

conceptualised and designed the paper, provided feedback, reviewed and revised the manuscript. All authors read and approved the final manuscript.

\section{Ethics approval and consent to participate}

Written informed consent to participate in the study was obtained from the parents of the patients.

\section{Consent for publication}

Written informed consent for publication of their clinical details and clinical images was obtained from the parents of the patients.

\section{Competing interests}

The authors declare that they have no competing interests.

\section{Publisher's Note}

Springer Nature remains neutral with regard to jurisdictional claims in published maps and institutional affiliations.

\section{Author details}

'Department of Pediatric Hematology/Oncology, Bambino Gesù Children's Hospital, IRCCS, Piazza di Sant'Onofrio 4, 00165 Rome, Italy. ${ }^{2}$ Department of Radiology, Bambino Gesù Children's Hospital, IRCCS, Piazza di Sant'Onofrio 4, 00165 Rome, Italy. ${ }^{3}$ Department of Laboratories - Pathology Unit, Bambino Gesù Children's Hospital, IRCCS, Rome, Italy. Piazza di Sant'Onofrio 4, 00165 Rome, Italy.

Received: 1 August 2017 Accepted: 30 April 2018

Published online: 15 May 2018

\section{References}

1. Ferrari A, Casanova M, Bisogno G, Zanetti I, Cecchetto G, De Bernardi B, Riccardi R, Tamaro P, Meazza C, Alaggio R, Ninfo V, Carli M, Italian Cooperative Group. Rhabdomyosarcoma in infants younger than one year old: a report from the Italian Cooperative Group. Cancer. 2003; 97(10):2597-604.

2. Ragab AH, Heyn R, Tefft M, Hays DN, Newton WA Jr, Beltangady M. Infants younger than 1 year of age with rhabdomyosarcoma. Cancer. 1986;58(12): 2606-10.

3. Koscielniak E, Harms D, Schmidt D, Ritter J, Keim M, Riehm H, Treuner J. Soft tissue sarcomas in infants younger than 1 year of age: a report of the German soft tissue sarcoma study group (CWS-81). Med Pediatr Oncol. 1989;17(2):105-10

4. Salloum E, Flamant F, Rey A, Caillaud JM, Friedman S, Valteau D, Lemerle J. Rhabdomyosarcoma in infants under one year of age: experience of the Institut Gustave-Roussy. Med Pediatr Oncol. 1989;17(5):424-8.

5. Orbach D, Rey A, Oberlin O, Sanchez de Toledo J, Terrier-Lacombe MJ, van Unnik A, Quintana E, Stevens MC. Soft tissue sarcoma or malignant mesenchymal tumors in the first year of life: experience of the International Society of Pediatric Oncology (SIOP) malignant mesenchymal tumor committee. J Clin Oncol. 2005;23(19):4363-71.

6. Lobe TE, Wiener ES, Hays DM, Lawrence WH, Andrassy RJ, Johnston J, Wharam M, Webber B, Ragab A. Neonatal rhabdomyosarcoma: the IRS experience. J Pediatr Surg. 1994;29(8):1167-70.

7. Dillon PW, Whalen TV, Azizkhan RG, Haase GM, Coran AG, King DR, Smith M. Neonatal soft tissue sarcomas: the influence of pathology on treatment and 
survival. Children's Cancer Group Surgical Committee. J Pediatr Surg. 1995; 30(7):1038-41.

8. Lawrence W Jr, Anderson JR, Gehan EA, Maurer H. Pretreatment TNM staging of childhood rhabdomyosarcoma: a report of the intergroup rhabdomyosarcoma study group. Children's cancer study group. Pediatric oncology group. Cancer. 1997;80:1165-70

9. Hayashi $Y$, Inaba T, Hanada R, Yamamoto K. Translocation 2;8 in a Congenital Rhabdomyosarcoma. Cancer Genet Cytogenet. 1988;30(2):343-5.

10. Onal B, Ozdemir H, Arac M, Oznur I, Isik S. Rhabdomyosarcoma of the prostate in a newborn: sonographic and CT findings. Eur J Radiol. 1995 Dec 15;21(2):106-8

11. Skelton VA, Goodwin A. Perinatal management of a neonate with airway obstruction caused by rhabdomyosarcoma of the tongue. Br J Anaesth. 1999;83(6):951-5.

12. Jogai S, Radotra BD, Joshi K. Congenital Paratesticular Rhabdomyosarcoma. Ped Path Mol Med. 2009;21(5):513-6.

13. Matsunaga GS, Shanberg AM, Rajpoot D. Prenatal Ultrasonographic Detection of Bladder Rhabdomyosarcoma. J Urol. 2003;169(4):1495-6.

14. Lee M-W, Chung W-K, Choi J-H, Moon K-C, Koh J-K. A case of botryoid-type Embryonal Rhabdomyosarcoma. Clin Exp Dermatol. 2009;34(8):e737-9.

15. Singh O, Gupta SS, Upadhyaya V, Sharma SS, Lahoti BK, Raj Mathur K. Rhabdomyosarcoma of the posterior chest wall in a newborn: a case report. Cases J. 2009:2(1):6818.

16. Meloni-Ehrig A, Smith B, Zgoda JA, Greenberg J, Perdahl-Wallace E, Zaman S, Mowrey P. Translocation (2;8)(q35; 13 ): a recurrent abnormality in congenital embryonal rhabdomyosarcoma. Cancer Genet Cytogenet. 2009; 191(1):43-5.

17. Kraft SM, Singh V, Sykes KJ, Gamis A, Manalang MA, Wei JL. Differentiating between congenital rhabdomyosarcoma versus fibromatosis of the pediatric tongue. Int J Pediatr Otorhinolaryngol. 2010;74(7):781-5.

18. Shahgholi E, Mollaian M, Haghshenas Z, Honarmand M. Congenital rhabdomyosarcoma, central precocious puberty, hemihypertrophy and hypophosphatemic rickets associated with epidermal nevus syndrome. J Pediatr Endocrinol Metab. 2011:24(11-12):1063-6.

19. Hala Megarbane, Francois Doz, Yves Manach, Christopher Fletcher, Francis Jaubert, Yves de Prost, Dominique Hamel-Teillac, (2011) Neonatal Rhabdomyosarcoma Misdiagnosed as a Congenital Hemangioma. Pediatr Dermatol 28 (3):299-301

20. Singh GB, Rai AK, Arora R, Garg S, Abbey P, Shukla S. A Rare Case of Congenital Simple Cystic Ranula in a Neonate. Case Rep Otolaryn. 2013; 2013:1-3.

21. Christman MP, Kerner JK, Cheng C, Piris A, Nepo AG, Sepehr A, Kroshinsky D. Rhabdomyosarcoma Arising in a Giant Congenital Melanocytic Nevus. Pediatr Dermatol. 2014;31(5):584-7.

22. Lee YC, Hsu YH, Yang SH, Huang TL. Congenital Eyelid Rhabdomyosarcoma. Ophthal Plast Reconstr Surg. 2016;32(5):e104-6.

23. Rodriguez-Galindo C, Hill DA, Onyekwere O, Pin N, Rao BN, Hoffer FA, Kun LE, Pappo AS, Santana VM. Neonatal alveolar rhabdomyosarcoma with skin and brain metastases. Cancer. 2001;92(6):1613-20.

24. Grundy R, Anderson J, Gaze M, Gerrard M, Glaser A, Gordon A, Malone M, Pritchard-Jones K, Michalski A. Congenital alveolar rhabdomyosarcoma: clinical and molecular distinction from alveolar rhabdomyosarcoma in older children. Cancer. 2001;91(3):606-12.

25. Hayashi K, Ohtsuki Y, Takahashi K, Sonobe H, Nakamura S-i, Kitagawa N, Arata J, Shimanouchi Y, Kurashige T. Congenital Alveolar Rhabdomyosarcoma with multiple skin metastases: Report of a Case. Pathol Int. 1988;38(2):241-8.

26. Kitagawa N, Arata J, Ohtsuki Y, Hayashi K, Oomori Y, Tomoda T. Congenital Alveolar Rhabdomyosarcoma Presenting as a Blueberry Muffin Baby. J Dermatol. 1989:16(5):409-11.

27. Schmidt D, Fletcher CDM, Harms D. Rhabdomyosarcomas with Primary Presentation in the Skin. Pathol Res Pract. 1993;189(4):422-7.

28. Ito F, Watanabe $Y$, Harada T, Horibe K. Cerebral metastases of alveolar rhabdomyosarcoma in an infant with multiple skin nodules. J Pediatr Hematol Oncol. 1997 Sep-Oct;19(5):466-9.

29. Godambe SV, Rawal J. Blueberry muffin rash as a presentation of alveolar cell rhabdomyosarcoma in a neonate. Acta Paediatr. 2000 Jan;89(1):115-7.

30. Brecher AR, Reyes-Mugica M, Kamino H, Chang MW. Congenital Primary Cutaneous Rhabdomyosarcoma in a Neonate. Pediatr Dermatol. 2003; 20(4):335-8.
31. Vankalakunti M, Das A, Rao NK. Postauricular congenital alveolar rhabdomyosarcoma- a case report of an unusual entity. Diagn Pathol. 2006 Oct 17;1:37

32. Rekhi B, Qureshi SS, Narula G, Gujral S, Kurkure P. Rapidly Progressive Congenital Rhabdomyosarcoma Presenting with Multiple Cutaneous Lesions: An Uncommon Diagnosis and a Therapeutic Challenge. Pathol Res Pract. 2014;210(5):328-33.

33. Carli M, Colombatti R, Oberlin $\mathrm{O}$, et al. European intergroup studies (MMT4-89 and MMT4-91) on childhood metastatic rhabdomyosarcoma: final results and analysis of prognostic factors. J Clin Oncol. 2004;22(23): 4787-94.

34. Bisogno G, Ferrari A, Prete A, Messina C, Basso E, Cecchetto G, Indolfi P, Scarzello G, D'Angelo P, De Sio L, Di Cataldo A, Carli M. Sequential high-dose chemotherapy for children with metastatic rhabdomyosarcoma. Eur J Cancer. 2009:45(17):3035-41.

35. Orbach D, Brennan B, De Paoli A, Gallego S, Mudry P, Francotte N, van Noesel M, Kelsey A, Alaggio R, Ranchère D, De Salvo GL, Casanova M, Bergeron C, Merks JH, Jenney M, Stevens MC, Bisogno G, Ferrari A. Conservative strategy in infantile fibrosarcoma is possible: the European paediatric soft tissue sarcoma study group experience. Eur J Cancer. 2016:57:1-9.

36. Mosquera JM, Sboner A, Zhang L, Kitabayashi N, Chen CL, Sung YS, Wexler LH, LaQuaglia MP, Edelman M, Sreekantaiah C, Rubin MA, Antonescu CR. Recurrent NCOA2 gene rearrangements in congenital/infantile spindle cell rhabdomyosarcoma. Genes Chromosom Cancer. 2013;52(6):538-50.

\section{Ready to submit your research? Choose BMC and benefit from:}

- fast, convenient online submission

- thorough peer review by experienced researchers in your field

- rapid publication on acceptance

- support for research data, including large and complex data types

- gold Open Access which fosters wider collaboration and increased citations

- maximum visibility for your research: over $100 \mathrm{M}$ website views per year

At BMC, research is always in progress.

Learn more biomedcentral.com/submissions 